\title{
Improving size selectivity of round pot for Charybdis japonica by configuring escape vents in the Yellow Sea, China
}

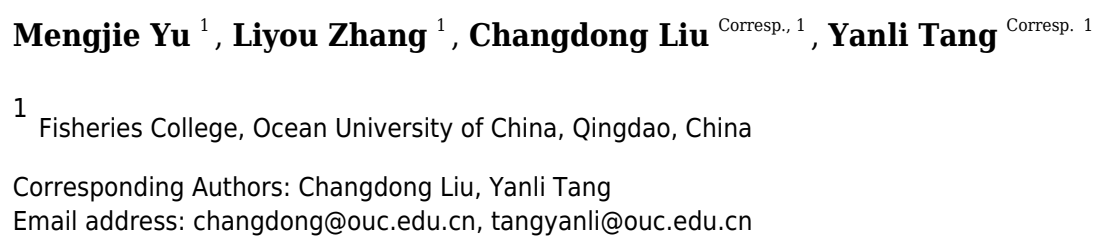

Sustainable development of the important economic species, Asian paddle crab (Charybdis japonica), has attracted attention in the coastal waters of the Yellow Sea, China. The commonly used round pots are almost nonselective, resulting in severe bycatch of juveniles. In this study, we explored a method to improve the size selectivity for $C$. japonica by mounting escape vents on the side panels of each pot. The selectivity of pots with escape vent sizes of $70 \times 20,70 \times 25,70 \times 30$, and $70 \times 35 \mathrm{~mm}$ was tested using a catch comparison method. The estimated minimum landing size (MLS) of carapace height (27 mm), according to the regulated MLS of carapace length (50 mm), was used as a reference point to explain the results. Significant increases in the size of crabs caught by pots were found with the enlargement of escape vent size (Kruskal-Wallis test, $P<0.01$ ). The pots with $70 \times 20,70 \times 25$ and $70 \times 30 \mathrm{~mm}$ escape vents released nearly $50 \%, 75 \%$ and $95 \%$ of undersized individuals, respectively, and these three types of pots retained approximately $90 \%$ of legal-sized individuals compared with the control pots without escape vents. The pots with $70 \times 35 \mathrm{~mm}$ escape vents released nearly all undersized individuals, but they also released most legal-sized individuals. Pots with an escape vent size of $70 \times 30 \mathrm{~mm}$ were recommended for the sustainable development of $C$. japonica in the Yellow Sea of China. The results of this study reiterate the importance of carapace height for determining the size selectivity, which can serve as a reference to formulate management regulations in the coastal waters of the Yellow Sea, China. 
3 Mengjie $\mathrm{Yu}^{1}$, Liyou Zhang ${ }^{1}$, Changdong Liu ${ }^{1}$, Yanli Tang ${ }^{1}$

$4 \quad{ }^{1}$ Fisheries College, Ocean University of China, Qingdao, Shandong, China

5

6 Corresponding author:

7 Changdong Liu ${ }^{1}$, Yanli Tang ${ }^{1}$

8 Fisheries College, Ocean University of China, No.5, Yushan Road, Qingdao, Shandong, 266003,

9 China

E-mail addresses: changdong@,ouc.edu.cn,tangyanli@,ouc.edu.cn 
12 Abstract: Sustainable development of the important economic species, Asian paddle crab

13 (Charybdis japonica), has attracted attention in the coastal waters of the Yellow Sea, China. The

14

commonly used round pots are almost nonselective, resulting in severe bycatch of juveniles. In this study, we explored a method to improve the size selectivity for C. japonica by mounting escape vents on the side panels of each pot. The selectivity of pots with escape vent sizes of $70 \times$ $20,70 \times 25,70 \times 30$, and $70 \times 35 \mathrm{~mm}$ was tested using a catch comparison method. The estimated minimum landing size (MLS) of carapace height $(27 \mathrm{~mm})$, according to the regulated MLS of carapace length $(50 \mathrm{~mm})$, was used as a reference point to explain the results. Significant increases in the size of crabs caught by pots were found with the enlargement of escape vent size (KruskalWallis test, $P<0.01$ ). The pots with $70 \times 20,70 \times 25$ and $70 \times 30 \mathrm{~mm}$ escape vents released nearly $50 \%, 75 \%$ and $95 \%$ of undersized individuals, respectively, and these three types of pots retained approximately $90 \%$ of legal-sized individuals compared with the control pots without escape vents. The pots with $70 \times 35 \mathrm{~mm}$ escape vents released nearly all undersized individuals, but they also released most legal-sized individuals. Pots with an escape vent size of $70 \times 30 \mathrm{~mm}$ were recommended for the sustainable development of $C$. japonica in the Yellow Sea of China. The results of this study reiterate the importance of carapace height for determining the size selectivity, which can serve as a reference to formulate management regulations in the coastal waters of the Yellow Sea, China.

Key words: Pot; Size selectivity; Escape vent; Logistic model; Minimum landing size; Charybdis japonica. 


\section{Introduction}

Crustacean fisheries represent an important part of marine commercial catches in China, recently comprising approximately $19.2 \%$ of the total landing (approx. 10 million tons) (Fisheries Administration Bureau, MARA, PRC, 2020). Crabs are among the most important crustacean catches and can be caught by many types of fishing gear, including trawls, gillnets, set nets, hoop nets, traps, and pots. Pots are well known for their high species selection and have become the main fishing gear for crabs (Yu et al., 2003; Vazquez Archdale \& Kuwahara, 2005; Song et al., 2006; Zhang et al., 2020).

Steel-framed round pots (hereafter 'round pots'), with the attributes of low cost and labor requirements, habitat friendliness and high catch efficiency, are widely used in the coastal waters of the Yellow Sea, China. Compared with commonly used fishing gear (e.g., trawls), round pots can be deployed in natural rocky/artificial reef areas. Round pots are also portable and easy to place aboard, enabling fishermen to work more efficiently. Furthermore, round pots are less prone to being wrecked and have a longer effective working life. Crabs caught by round pots have high quality, as most of them are alive and undamaged when landing, achieving a higher price in the market.

The Asian paddle crab, Charybdis japonica, belonging to settlement crustaceans, is widely distributed in the muddy, sandy and rocky/reef areas of the coastal waters of China, Korea, Japan and Southeast Asia at depths of 9-45 m (Vazquez Archdale \& Kuwahara, 2005; Zhang et al., 2016). Because of its high nutritional and economic value, $C$. japonica is an important commercial species and is one of the most important targeted species for round pots in the Yellow Sea of China. 
54 This species matures at a carapace length $(C L)$ of $50 \mathrm{~mm}$, so a minimum landing size (MLS) of 50

mm $C L$ was formulated according to decree No. 34 of the Chinese Ministry of Agriculture. The MLS of carapace height $(\mathrm{CH})$ was estimated to be $27 \mathrm{~mm}$ based on the relationship between $C L$ and $\mathrm{CH}$ for $\mathrm{C}$. japonica (see Section 3).

Despite the good attributes mentioned above, the currently used round pots in the Yellow Sea of China present poor selectivity for $C$. japonica due to their small mesh size $(25 \mathrm{~mm})$. In recent decades, many researchers have sought to improve the size selectivity of pots for different species by mounting escape vents/gaps, increasing mesh size, modifying mesh shape, and adjusting pot shape or entrance design (Guillory \& Hein S, 1998; Vazquez Archdale \& Kuwahara, 2005; Vazquez Archdale et al., 2007; Boutson et al., 2009; Broadhurst, Millar \& Hughes, 2017, 2018; Broadhurst et al., 2019). Installing escape vents or gaps has been proven to be a more convenient and effective measure to improve selectivity and optimize catching efficiency in different pot fisheries (e.g., Brown, 1982; Tallack, 2007; Boutson et al., 2009; Rotherham et al., 2013). Meanwhile, this method is more precise for size selection than enlargement of mesh size (Nishiuchi, 2001; Winger \& Walsh, 2007).

According to behavioral observations in the laboratory, crabs seek to escape from the vents by side-crawling, so the size selectivity of $C$. japonica for $C L$ depends on the vent length, and $C H$ depends on the vent width (Boutson et al., 2009). Although several studies have investigated the effect of escape vent length on the size selectivity of crabs (Zhang \& Zhang, 2013; Zhang et al., 2016; Broadhurst, Millar \& Hughes, 2018), comprehensive studies on the size selectivity of escape vents for $C$. japonica in the Yellow Sea of China have not been performed. 
In this study, we improved the size selectivity of round pots for $C$. japonica by mounting

76

77

escape vents from a small-scale fishery in the coastal waters of the Yellow Sea, China. We tested the size selectivity of four different escape vent width sizes $(20,25,30$, and $35 \mathrm{~mm})$ with a fixed escape vent length of $70 \mathrm{~mm}$ using a catch comparison method. Five selective models were tested, and the best model was selected. The main objective of this study was to quantify the size selectivity of escape vents for $C$. japonica using selective models and exploitation pattern indicators and then recommend an optimal escape vent size for this species considering local fishermen's profit and resource sustainability.

\section{Materials and methods}

2.1 Gear modification

The conventional round pot, which is commonly used in the coastal waters of the Yellow Sea, China, is cylindrical in shape with a height of $25 \mathrm{~cm}$ and diameter of $55 \mathrm{~cm}$. Each pot consists of 6 components, including a rigid steel frame, cover net (PE-36tex $\times 4 \times 3$; R12tex S/Z), funnel net $(\mathrm{PE}-36$ tex $\times 2 \times 3 ;$ R6tex $\mathrm{S} / \mathrm{Z})$, bait basket, mouth rope $(\mathrm{PE}-36$ tex $\times 25 \times 3 ; \mathrm{R} 75$ tex $\mathrm{S} / \mathrm{Z})$ and hook. The transversal and longitudinal mesh numbers of the cover net are 31 and 67, respectively, and those of the funnel net are 14 and 36, respectively. The mesh sizes ( \pm SD) of the cover net and funnel net are $25 \mathrm{~mm}( \pm 0.09)$ and $20 \mathrm{~mm}( \pm 0.10)$, respectively.

The round pot has six sides in total, three of which have funnel-shaped entrances. Laboratory observations showed that the bottom of the side panel was the best position for crabs to escape. Therefore, three escape vents cut from a board (thickness: $5 \mathrm{~mm}$ ) made from PMMA (polymethyl methacrylate) were mounted on the bottom of the three sides and fixed by nylon cable ties (HDS- 
$965 \times 350 \mathrm{~mm}$, quantity $250 \mathrm{pcs}$, tension $22 \mathrm{~kg} / 50 \mathrm{lbs}$, bundle diameter 3-90 mm) (Fig. 1). We

97 modified the round pot with four different escape vent sizes (length $\times$ width: $70 \times 20 \mathrm{~mm}, 70 \times 25$

$98 \mathrm{~mm}, 70 \times 30 \mathrm{~mm}$, and $70 \times 35 \mathrm{~mm}$ ). The length of each escape vent was set uniformly as $70 \mathrm{~mm}$

99 to ensure that $C$. japonica was not affected by $C L$ for escapement. The concrete pot modification

100 is shown in Fig. 1.

1012.2 Sea trials

102 The fishing experiment was conducted in the coastal waters of the Yellow Sea, China $103\left(35^{\circ} 15^{\prime} 0^{\prime \prime}-35^{\circ} 16^{\prime} 30^{\prime \prime} \mathrm{N}\right.$ and $\left.119^{\circ} 28^{\prime} 30^{\prime \prime}-119^{\circ} 30^{\prime} 0^{\prime \prime} \mathrm{E}\right)$ from August 19 to September 7,2020 . The 104 study area is a traditional fishing ground for $C$. japonica and was deployed artificial reefs from 1052005 to 2014 . The crab populations are more abundant in this area than those in the natural sea 106 area, making us to catch enough crabs to conduct the selectivity analysis. The sampling sites were 107 selected based on the recommendation of an experienced local fisherman (Fig. 2).

108 In the sea trials, we used the catch comparison method, and a total of 50 pots were deployed, 109 including 10 conventional pots as the control group and 40 modified pots (ten pots for each type) 110 as the test group. Control pots with $25 \mathrm{~mm}$ mesh size were assumed to be non-selective, so their 111 catch is representative of the stock in the fishing ground. Ten pots (two control pots and two pots 112 with $70 \times 20,70 \times 25,70 \times 30$, and $70 \times 35 \mathrm{~mm}$ escape vents) were connected into a string with a 113 random sequence. A total of 5 strings were used during the experiment, and each end of the string 114 was connected with buoys and anchors (weighing $15 \mathrm{~kg}$ per anchor) (Fig. 1). A local vessel, the 115 “Lurigangyu 77369” (LOA $8.3 \mathrm{~m}$, width $3.2 \mathrm{~m}$, height $0.85 \mathrm{~m}$, weight $4.0 \mathrm{GT}$, power $16.2 \mathrm{Kw}$ ), 116 with a vessel speed of approximately 3.0 knots and operated by three experienced local fishermen, 
117 was used to deploy and retrieve pots. Pots were deployed $50 \mathrm{~m}$ apart to ensure independence at a 118 water depth of 12-14 m and baited with Mytilus edulis, approximately $150 \mathrm{~g}$ per pot. All pots were 119 hauled up in the morning after approximately 2 days of soaking time, catches were collected, and then the pots were replaced in their original location.

All crabs captured were measured for $C L$ (the distance from the frontal notch to the posterior margin of the carapace), carapace width $(\mathrm{CW}$, defined as the distance between the ninth anterolateral spines), and $\mathrm{CH}$ (measured from the base of the second sternal segment to the highest part of the gastric region) to the nearest $\mathrm{mm}$ and for weight $(W)$ to the nearest $0.01 \mathrm{~g}$.

\subsection{Model for size selection}

The SELECT (Share Each Length's Catch Total) method was used to estimate the size selectivity by analyzing the proportion of individuals caught by each type of pot (for each $\mathrm{CH}$ class). The retention rate ( $\left.\Phi_{j C H}\right)$ of individuals in class $C H$ caught by pots with $j$-sized escape vents versus the total catch can be expressed as follows:

$$
\Phi_{j C H}=\frac{N_{j C H}}{\sum_{j}^{n} N_{j C H}}=\frac{p_{j} s_{j}(C H, v)}{\sum_{j}^{n} p_{j} s_{j}(C H, v)}
$$

where $N_{j C H}$ is the number of individuals in the $C H$ class caught by pots with $j$-sized escape vents, $p_{j}$ is the relative fishing intensity (defined as the probability that an individual entered the round pot with a $j$-sized escape vent, given that it entered the combined (test and control) gears), $\Sigma_{j}$ $p_{j}=1$, and $s_{j}(C H, v)$ is the retention probability with the unknown selectivity parameter vector $v$ (Wileman et al., 1996; Yang, Tang \& Liang, 2011; Tang et al., 2019). 
$137(\mathrm{CH}, v)$. Five different models were chosen as candidates to describe $s_{a v}(\mathrm{CH}, v):$ Logit, Probit, 138 Log-log, Clog-log, and Richards. The vector $v$ consists of two selectivity parameters, $\mathrm{CH} 50(\mathrm{CH}$ 139 of $C$. japonica with $50 \%$ probability of being retained) and SR (difference in $C H$ of $C$. japonica 140 with $25 \%$ and $75 \%$ probability of being retained). The Richard model needs one additional 141 parameter $(1 / \delta)$ to describe the asymmetry of the size selection curve. Detailed information about 142 these models can be found in Wileman et al. (1996).

143 To estimate the parameter values that make the experimental data most likely to be observed, 144 selectivity parameters and the relative fishing intensity $p_{j}$ were determined by maximizing the log145 likelihood function as follows:

$$
\sum_{j} \sum_{C H} N_{j C H} \ln \Phi_{j}(C H)
$$

where the two sums are for pot deployments conducted with the $j$-sized escape vent and $\mathrm{CH}$ classes, respectively.

The capacity of each model to fit the data was inspected based on the goodness-of-fit ( $p$ value) as described by Wileman et al. (1996). The model performances were compared based on

Akaike information criterion (AIC) values, and the best model was selected with the lowest AIC value (Akaike, 1974). We used the best model to model the selectivity curves.

Once the size selection model was identified, a double bootstrap method was used to estimate the $95 \%$ confidence interval $(C I)$ for the size selection curves and the corresponding parameters. This method is identical to the one used in Millar (1993), which takes both between-haul and within-haul variation into consideration. 
158

159

160

161

162

163

164

165

166

167

168

169

170

171

172

173

174

175

176

retention rates were estimated as follows:

$$
\begin{array}{r}
\delta_{1} s(\mathrm{CH})=s_{70 \times 20}(\mathrm{CH})-s_{\text {control }}(\mathrm{CH}) ; \delta_{2} S(\mathrm{CH})=s_{70 \times 25}(\mathrm{CH})-s_{70 \times 20}(\mathrm{CH}) ; \\
\delta_{3} s(\mathrm{CH})=s_{70 \times 30} \quad(\mathrm{CH})-s_{70 \times 25}(\mathrm{CH}) ; \quad \delta_{4} s(\mathrm{CH})=s_{70 \times 35} \quad(\mathrm{CH})-s_{70 \times 30} \quad(\mathrm{CH})
\end{array}
$$

$\delta s(\mathrm{CH})$ varies from -1 to 1 and for those $\mathrm{CH}$ classes in which the $\mathrm{CI}$ for $\delta s(\mathrm{CH})$ did not contain 0.0 , indicating a significant difference in selectivity between the two escape vents.

All estimates were obtained using the software tool R ( $R$ Core Team, 2018), and 1000 bootstrap repetitions were conducted to obtain CIs based on the "boot" package.

\subsection{Estimation of exploitation pattern indicators}

Exploitation pattern indicators were used to assess the capture efficiency considering the size structure of the population caught during the sea trials (Brinkhof et al., 2020). Because the escape vent length was fixed and the escape vent width depended on the $\mathrm{CH}$, the relationship between the $\mathrm{CH}$ and $\mathrm{CL}$ of $\mathrm{C}$. japonica was built to calculate the MLS of $\mathrm{CH}$ based on the formulated MLS of $C L(50 \mathrm{~mm})$. To evaluate how the escape vents would affect a specific fishery and estimate the percentages of individuals retained (in number) below and above the MLS of $\mathrm{CH}$, three exploitation pattern indicators, $n P_{-}, n P_{+}$and $n$ Ratio $\left(n\right.$ Ratio $\left.=n P_{-} / n P_{+}\right)$(Eq. (4)), were calculated for each test pot using the individuals caught in the control pot as the baseline. These indicators are expressed as:

$$
n P_{-}=100 \times \frac{\sum_{j} \sum_{c h<M L S} n T_{j c h}}{\sum_{j} \sum_{c h<M L S} n C_{j c h}}
$$




$$
\begin{array}{r}
n P_{+}=100 \times \frac{\sum_{j} \sum_{c h \geq M L S} n T_{j c h}}{\sum_{j} \sum_{c h \geq M L S} n C_{j c h}} \\
n \text { Ratio }=\frac{\sum_{j} \sum_{c h<M L S} n T_{j c h}}{\sum_{j} \sum_{c h \geq M L S} n T_{j c h}}
\end{array}
$$

where the summation of $j$ is over hauls with a specific escape vent size, and $c h$

is over $C H$ classes. $n T_{j c h}$ and $n C_{j c h}$ represent the number of individuals of $C H$ class in haul $j$ found

in the test and control pots, respectively. $n P_{-}$and $n P_{+}$indicate the retention efficiency of test pots for individuals below and above the MLS of $\mathrm{CH}$. A lower value of $n P_{-}$and a higher value of $n P_{+}$indicate that the pots release more undersized individuals and retain more legal-sized individuals, which is beneficial to the sustainable development of fishery resources. nRatio indicates the ratio of undersized and legal-sized individuals retained.

The above indicators were based on the number of individuals, but the value of catch was more related to weight. Therefore, the relationship between $\mathrm{CH}$ and $\mathrm{W}$ was built, and similar indicators $\left(w P_{-}, w P_{+}, w R a t i o\right)$ based on weight were also estimated:

$$
w P_{-}=100 \times \frac{\sum_{j} \sum_{c h<M L S}\left\{w_{c h} \times n T_{j c h}\right\}}{\sum_{j} \sum_{c h<M L S}\left\{w_{c h} \times n C_{j c h}\right\}}
$$

$$
w P_{+}=100 \times \frac{\sum_{j} \sum_{c h \geq M L S}\left\{w_{c h} \times n T_{j c h}\right\}}{\sum_{j} \sum_{c h \geq M L S}\left\{w_{c h} \times n C_{j c h}\right\}}
$$

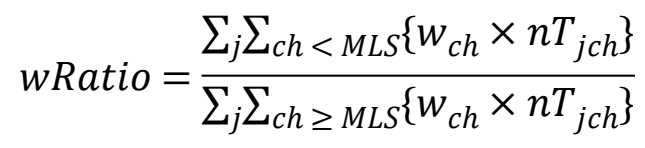

The double bootstrap method was used to estimate the Efron percentile 95\% confidence limits for the indicators $\left(n P_{-}, n P_{+}, n\right.$ Ratio, $w P_{-}, w P_{+}, w$ Ratio $)$ considering both the effect of between-pot variation and the uncertainty related to within-pot variation (Herrmann et al., 2012; 
195

196

197

198

199

200

201

202

203

204

205

206

207

208

209

210

211

212

213

214

215

Cheng et al., 2019; Kalogirou et al., 2019).

Kruskal-Wallis test was used to examine whether there was a significant increase in the size of crabs caught by the pots with the enlargement of escape vent size. The significance of $n P_{-}$and $n P+$ were also examined using the Kruskal-Wallis test. With the comprehensive consideration of the released rate of undersized individuals and retained rate of legal-sized individuals, we recommended an optimal escape vent size for $C$. japonica.

\section{Results}

A total of 50 pots (ten for each type) were used during the 20 -day sea trials, one pot was lost, and supplementation was conducted in a timely manner. None of the PMMA board was fractured or fell off. A total of $704 \mathrm{C}$. japonica were caught in 9 hauls, ranging in $\mathrm{CH}$ from 9 to $45 \mathrm{~mm}$ and accounting for $64 \%$ and $70 \%$ of the total catch number and weight, respectively. The number of C. japonica in pots with different escape vent sizes (control, $70 \times 20,70 \times 25,70 \times 30$, and $70 \times$ $35 \mathrm{~mm}$ ) was $250,165,126,99$, and 64 , respectively. The $C H$ distribution of $C$. japonica caught in each type of pot is shown in Fig. 3. There was a significant increase in the size of retained crabs with the enlargement of escape vent size (Kruskal-Wallis test, $P<0.01$ ) (Table 1). The by-catch species included Rapana venosa, Palaemon ortmanni, Pennahia argentata, and Asterinidae. The catch species composition of different pot types was similar and the catch rates of by-catch decreased with the enlargement of escape vent size (Table 1).

The five selectivity models (Logit, Loglog, Probit, Cloglog, and Richard) provided acceptable $p$-values $(p>0.05)$, showing that they were well fitted for the data. The traditional logistic model was selected as the best model because of its lowest AIC value, so the following results were 
216

217

218

219

220

221

222

223

224

225

226

227

228

229

230

231

232

233

234

235

236

obtained based on this model.

The estimated relationships between $C H$ and $C L, W$ and $C H$ can be described as:

$$
\begin{gathered}
C H=0.62 C L-3.88 R^{2}=0.98 \\
W=1.12 \times 10^{-2} C H^{2.62} R^{2}=0.89
\end{gathered}
$$

The MLS of $C H$ was calculated as $27 \mathrm{~mm}$ based on the formulated MLS of $C L(50 \mathrm{~mm})$.

The CH50 was estimated at $10.73 \mathrm{~mm}$ (CI: 10.45-10.91), 18.23 mm (CI: 17.98-18.43), 23.19

$\mathrm{mm}(C I: 22.93-23.85), 25.73 \mathrm{~mm}(C I: 25.02-26.25)$, and $31.79 \mathrm{~mm}(C I: 30.80-32.52)$ for the control pot and escape vent sizes of $70 \times 20,70 \times 25,70 \times 30,70 \times 35 \mathrm{~mm}$, respectively (Table 2), demonstrating that the CH50 increased with increasing escape vent size. The SR was estimated at $4.97 \mathrm{~mm}$ (CI: 4.61-5.28), $4.23 \mathrm{~mm}$ (CI: 3.93-4.54), $3.79 \mathrm{~mm}$ (CI: 3.60-4.13), $2.40 \mathrm{~mm}$ (CI: $2.11-$ 2.52), and $2.74 \mathrm{~mm}(C I: 2.38-3.05)$ for the five pot types, respectively (Table 2$)$. The SR decreased with increasing escape vent size. Based on the estimated parameters, the mean size selectivity curves and their $C I s$ are shown in Fig. 3 with MLS of $C H(27 \mathrm{~mm})$ as the reference point. The relative fishing intensity was estimated to be $0.20,0.19,0.18,0.22$, and 0.21 for the five pot types, indicating that an individual had a similar probability of entering any of the five pot types. The estimated relative size selectivity curves are shown in Fig. 4.

For the test pots, exploitation pattern indicators showed that the catch efficiency of undersized individuals significantly decreased with increasing escape vent size (Kruskal-Wallis test, $P<0.01)$. For instance, the pot with $70 \times 20 \mathrm{~mm}$ escape vent retained $48.32 \%(C I: 45.33-51.68 \%)$ of individuals below the MLS ( $n P-)$; by comparison, $n P$ - would drop to $24.83 \%$ (CI: $21.34-28.28 \%$ ) for the $70 \times 25 \mathrm{~mm}$ escape vent, and less than $10 \%$ for the $70 \times 30$ and $70 \times 35 \mathrm{~mm}$ escape vents, 
237 respectively (Table 3). However, the pots with large escape vent sizes might compromise 238 decreasing catch efficiency for the legal-sized individuals. For the first three types of test pots (70 $239 \times 20,70 \times 25$, and $70 \times 30 \mathrm{~mm}$ ), a slightly lower catch efficiency was observed for legal-sized 240 individuals $(n P+>88 \%)$, while the catch efficiency of legal-sized individuals decreased 241 significantly for the pot with $70 \times 35 \mathrm{~mm}$ escape vent (Kruskal-Wallis test, $P<0.01$ ), dropping by 242 nearly $40 \%$ in the number. The additional indicators, $w P$ - and $w P+$, reflected a similar trend to $243 n P$ - and $n P+$. Of note, the $w P+$ of test pots $(70 \times 20,70 \times 25$, and $70 \times 30 \mathrm{~mm})$ indicated no 244 significant loss of catch efficiency for legal-sized individuals in the weight, as the $C I$ contained $245100 \%$ (Table 3).

Fig. 5 shows the difference between the $\mathrm{CH}$-dependent retention rates of different pot types.

247 It is obvious that the increase in escape vent size significantly decreases the retention probability 248 for undersized individuals, as the $C I s$ of the four curves do not contain 0 . For the first three delta plots, the difference in retention rates of undersized individuals gradually increases with increasing escape vent sizes and reaches the maximum values of $98 \%, 81 \%$, and $54 \%$ in the $\mathrm{CH}$ classes of 14,21 , and $24 \mathrm{~mm}$, respectively, while there is no difference in retention rates for legal-sized individuals. This result indicates that pots with $70 \times 30 \mathrm{~mm}$ escape vents are the most efficient at releasing undersized individuals while maintaining catch efficiency for legal-sized individuals. For the last delta plots, the difference in the retention rates for legal-sized individuals is significant and reaches the maximum values of $99 \%$ in the $C H$ class of $29 \mathrm{~mm}$. This result shows that pot with 70 $\times 35 \mathrm{~mm}$ escape vent is less efficient at retaining the legal-sized individuals.

\section{Discussion}


This study presented novel results regarding the round pot selectivity and selection range of

C. japonica from a small-scale fishery in the coastal waters of the Yellow Sea, China. Although

several studies have investigated the performance of escape vents in pot fisheries (e.g., Boutson et

Millar \& Hughes, 2018; Broadhurst et al., 2019), this study is the first to (1) systematically do

research on the size selectivity of round pots for $C$. japonica in the coastal waters of the Yellow

Sea, China, using a catch comparison method; (2) estimate the width of escape vents on the size

selectivity of C.japonica; and (3) use a statistical approach to estimate individual fractions retained

below and above the MLS of $C H$ of $C$. japonica.

When crabs try to escape from the escape vents, they firstly side-crawl to the vents and then

swim up and down to squeeze the body out the vents with the help of limbs and cheliped. $\mathrm{CH}$

limited the escape rate greatly according to the escape behaviour of $C$. japonica. Thus, we used

$\mathrm{CH}$ instead of $\mathrm{CL}$ for determining size selectivity of escape vent (Stasko, 1975; Brown, 1982;

Treble, Millar \& Walker, 1998; Rotherham et al., 2013; Broadhurst, Butcher \& Cullis, 2014;

Broadhurst, Butcher \& Millar, 2017). An MLS of CL (50 mm) was formulated for C. japonica in

China, but it does not discriminate between male and female populations, so we did not determine

the males and females retained in the pots. The difference in mature length of male and female $C$.

japonica implies sex ratio is valuable information in assessing the size selectivity of round pot for

C. japonica, and this information will be accounted for in our future research (Zhang et al., 2016).

The estimated MLS of $C H$ was $27 \mathrm{~mm}$ based on the relationship between $C L$ and $C H$, as crabs 
$279\left(\mathrm{R}^{2}=0.98\right)$ between $C L$ and $C H$ indicates that we defined exploitation pattern indicators and 280 explained the study results using the MLS of $\mathrm{CH}$ as the reference point was appropriate. The ideal gear will retain all legal-sized individuals and release all undersized individuals (Guillory et al., 2004). However, escape vent selectivity is gradual, and crabs become less likely to escape with the increased size (Guillory \& Merrell, 1993). Thus, the fractions retained in the pots below and above the MLS and the ratio between them can be good indicators of selective performance of fishing gear.

The results of this study indicated significant differences in size selectivity among pots with different-sized escape vents. The control pots presented poor selectivity, as the CH50 (10.73 mm) was well below the MLS of $C H(27 \mathrm{~mm})$, which will weaken the sustainability of fishery resources.

With the installation of large escape vents, the CH50 increased considerably, implying that escape vents can effectively improve the size selectivity of round pots. This result is consistent with the published researches on the other commercially important crustacean pot fisheries (e.g., Guillory et al., 2004; Arana, Orellana \& De Caso, 2011; Rotherham et al., 2013; Broadhurst, Millar \& Hughes, 2017; Broadhurst, Butcher \& Millar, 2017; Broadhurst \& Millar, 2018a; Gandy et al., 2018). The exploitation indicators indicated that the pots with $70 \times 20,70 \times 25$ and $70 \times 30 \mathrm{~mm}$ escape vents released nearly $50 \%, 75 \%$ and $95 \%$ of the undersized individuals, respectively, and these three types of pots retained approximately $90 \%$ of the legal-sized individuals compared with control pots without escape vents. The pot with $70 \times 35 \mathrm{~mm}$ escape vent released all undersized individuals. However, they presented low catch efficiency for legal-sized individuals, as nearly 
300 Thus, more fishing effort is needed to compensate for the loss of legal-sized individuals. We

301 recommend $70 \times 30 \mathrm{~mm}$ as the most appropriate size for escape vents mounted on the round pots

302 for $C$. japonica in the Yellow Sea of China following comprehensive consideration of local

303 fishermen's profits and resource sustainability.

304 Several studies found that a reduction in undersized crab retention resulted in a higher catch

of legal-sized crabs by avoiding the " pot saturation" phenomenon (e. g., Fogarty \& Borden, 1980;

Brown, 1982; Guillory \& Merrell, 1993; Havens et al., 2009; Arana, Orellana \& De Caso, 2011;

Zhang et al., 2016; Broadhurst, Butcher \& Millar, 2017; Zhang et al., 2020). However, the number

of legal-sized crabs was slightly lower in the test pots with $70 \times 20,70 \times 25$, and $70 \times 30 \mathrm{~mm}$

escape vents than in the control pots without escape vents. This similar finding with the previous

studies was probably caused by the low density of crabs in the fishing area (Eldridge, Burrell \&

Steele, 1979; Guillory \& Prejean, 1997; Treble, Millar \& Walker, 1998; Guillory et al., 2004;

Jirapunpipat et al., 2008; Boutson et al., 2009; Broadhurst \& Millar, 2018a), as we found that

mean catch rates for legal-sized individuals were well below saturation thresholds. Species-

specific behavioral interactions (e.g. competitive behaviors for food and space), size-specific

distributions, and gear-specific factors (e.g. pot shape, volume, materials, entrance design and

numbers) may also affect the entry and escape process when considering the passive capture

characteristic of pot (Kim \& Ko, 1987; Yamane \& Hiraishi, 2002; Vazquez Archdale et al., 2003,

2007; Montgomery, 2005; Vazquez Archdale \& Kuwahara, 2005; Vazquez Archdale, Añasco \&

Hiromori, 2006; Butcher et al., 2012; Broadhurst, Butcher \& Millar, 2017). 
321 of pot gear (Boutillier \& Sloan, 1987; Montgomery, 2005; Nguyen et al., 2020). The retention of

322 small-sized individuals can be reduced by increasing the soak time due to the long time for 323 escaping (Treble, Millar \& Walker, 1998; Vazquez Archdale et al., 2007; Winger \& Walsh, 2011;

324 Olsen et al., 2019). Bait attractiveness will decrease with time, and we found that bait was depleted

325 when retrieving the pots during the sea trials. Thus, a soaking time of 2 days in our sea trials could provide sufficient chance for crabs to escape. Previous studies have shown that $C$. japonica could quickly detect the bait, then enter the pot to consume the bait, and final escape (Vazquez Archdale,

Kariyazono \& Añasco, 2006; Vazquez Archdale et al., 2007). Other species (by-catch), in addition to crabs, can also be trapped in the pots, and these species could have also fed on the bait. The availability of baits/lures could have affected the entry of crabs. This may also be a reason for the failure to detect a significant increase in the pots with escape vents in catchability for legal-sized individuals.

Ocean currents may cause discrepant catch effectiveness of round pots for undersized and

legal-sized individuals because of the size-dependent swimming ability of crabs. However,

Vazquez Archdale et al. (2003) found that most crabs (75\%) crawled towards the pots downstream

following the bait odor. This downstream swimming behaviour implies ocean currents will not cause quite different catch efficiency of traps for undersized and legal-sized individuals. Moreover, the entrances on the three sides of round pot provide much chance for undersized individuals to enter the gear. Further research using underwater video will provide more knowledge to verify this inference.

Escape openings are mandated in many crustacean fisheries around the world, such as 
342 Australian lobster fisheries and North American blue crab fishery (Treble, Millar \& Walker, 1998;

343 Guillory et al., 2004; Broadhurst, Butcher \& Millar, 2017). The annual marine Charybdis landings

344 have decreased from 62,581 to 24,259 tons (2010-2019) in China caused by environmental

345 pollution, over-use of poor-selective fishing gears, and excessive fishing efforts, and this has raised

346 immediate concerns of the Chinese government on restoring the coastal eco-system. Configuring

347 a suitable escape vent was regarded as a simple and effective solution to conserve fisheries

348 resources, mitigate ghost fishing mortality and achieve a balanced harvest in pot fisheries (Boutson

349 et al., 2009; Arana, Orellana \& De Caso, 2011; Uhlmann \& Broadhurst, 2015; Broadhurst \&

350 Millar, 2018b; Gandy et al., 2018). The widespread use of pots in the coastal areas of China means

351 that even marginal improvements in selectivity are likely to have considerable cumulative

352 environmental and ecological benefits.

353 5. Conclusion

354 In this research, we configured the escape vents on the round pots to improve the size 355 selectivity of $C$. japonica in the coastal waters of the Yellow Sea, China. The catch comparison 356 trials were conducted in the sea and the selective performances of four different escape vent width 357 sizes $(20,25,30$, and $35 \mathrm{~mm})$ with a fixed escape vent length of $70 \mathrm{~mm}$ were estimated. Five 358 candidate selectivity models were compared and logistic model was selected as the best to describe 359 the selectivity curves. The currently used pots are almost nonselective because of small mesh sizes, 360 and configuring escape vents can significantly improve the size selectivity of $C$. japonica. With 361 comprehensive analysis of the retention rate of legal-sized individuals and the escape rate of 362 undersized individuals, pots with an escape vent size of $70 \times 30 \mathrm{~mm}$ were recommended 
363 considering local fishermen's profits and resource sustainability. This study can serve as a 364 reference to develop more detailed fishery management regulations in the coastal waters of the 365 Yellow Sea, China.

366

367

368

369

370

371

372

373

374

375

376

377

378

379

380

381

382

383

\section{Acknowledgments}

This study was supported by the Project of Marine and Fishery Technology Innovation of Shandong (No. 2017HYCX007). We thank the Rizhao Fisheries Group Company for providing assistance, and we express our gratitude to Captain Teng for his advice and help during the sea trials.

Yu M.J. and Tang Y.L. conceived the idea; Yu M.J. and Zhang L.Y. designed the sampling; Yu M.J. and Liu C.D. analyzed the data and interpreted the results. All authors carried out the writing of manuscript and approve the final version of the manuscript.

\section{References}

Akaike H. 1974. A new look at the statistical model identification. IEEE Transactions on Automatic Control 19: 716-723.

Arana PM, Orellana JC, De Caso Á. 2011. Escape vents and trap selectivity in the fishery for the Juan Fernández rock lobster (Jasus frontalis), Chile. Fisheries Research 110: 1-9. DOI: 10.1016/j.fishres.2011.03.021.

Boutillier JA, Sloan NA. 1987. Effect of trap design and soak time on catches of the British Columbia prawn (Pandalus platyceros). Fisheries Research 6: 69-79. DOI: $10.1016 / 0165-7836(87) 90007-5$. 
384 Boutson A, Mahasawasde C, Mahasawasde S, Tunkijjanukij S, Arimoto T. 2009. Use of escape

385

386

387

388

389

390

391

392

393

394

395

396

397

398

399

400

401

402

403

404 vents to improve size and species selectivity of collapsible pot for blue swimming crab Portunus pelagicus in Thailand. Fisheries Science 75: 25-33.

DOI: $10.1007 / \mathrm{s} 12562-008-0010-\mathrm{z}$.

Brinkhof J, Larsen RB, Herrmann B, Sistiaga M. 2020. Size selectivity and catch efficiency of bottom trawl with a double sorting grid and diamond mesh codend in the North-east Atlantic gadoid fishery. Fisheries Research 231: 105647.

DOI: 10.1016/j.fishres.2020.105647.

Broadhurst MK, Butcher PA, Cullis BR. 2014. Effects of Mesh Size and Escape Gaps on Discarding in an Australian Giant Mud Crab (Scylla serrata) Trap Fishery. PLoS ONE 9: e106414. DOI: 10.1371/journal.pone.0106414.

Broadhurst MK, Millar RB, Hughes B. 2017. Performance of industry-developed escape gaps in Australian Portunus pelagicus traps. Fisheries Research 187: 120-126.

DOI: 10.1016/j.fishres.2016.11.013.

Broadhurst MK, Butcher PA, Millar RB. 2017. Escape gaps in recreational panulirid traps: Reducing catches of undersized Sagmariasus verreauxi while increasing fishing power for legal sizes. Fisheries Research 189: 55-61.

DOI: 10.1016/j.fishres.2017.01.006.

Broadhurst MK, Millar RB, Hughes B. 2018. Utility of multiple escape gaps in Australian Scylla serrata traps. Fisheries Research 204: 88-94.

DOI: 10.1016/j.fishres.2018.01.017. 
405

406

407

408

409

410

411

412

413

414

415

416

417

418

419

420

421

422

423

424

425

Broadhurst MK, Millar RB. 2018a. Configuring escape gaps in recreational rectangular traps to improve size selection for eastern rock lobster, Sagmariasus verreauxi. Fisheries Research 207: 182-186. DOI: 10.1016/j.fishres.2018.05.027.

Broadhurst MK, Millar RB. 2018b. Relative ghost fishing of portunid traps with and without escape gaps. Fisheries Research 208: 202-209.

DOI: $10.1016 /$ j.fishres.2018.07.018.

Broadhurst MK, Smith TM, Millar RB, Hughes B, Raoult V, Gaston TF. 2019. Cumulative selectivity benefits of increasing mesh size and using escape gaps in Australian Portunus armatus traps. Fisheries Management and Ecology 26: 319-326. DOI: 10.1111/fme.12351.

Brown CG. 1982. The effect of escape gaps on trap selectivity in the United Kingdom crab (Cancer pagurus L.) and lobster (Homarus gammarus (L.)) fisheries. ICES Journal of Marine Science 40: 127-134. DOI: 10.1093/icesjms/40.2.127.

Butcher PA, Leland JC, Broadhurst MK, Paterson BD, Mayer DG. 2012. Giant mud crab (Scylla serrata): relative efficiencies of common baited traps and impacts on discards. ICES Journal of Marine Science 69: 1511-1522.

DOI: $10.1093 /$ icesjms/fss 109 .

Cheng Z, Einarsson HA, Bayse S, Herrmann B, Winger P. 2019. Comparing size selectivity of traditional and knotless diamond-mesh codends in the Iceland redfish (Sebastes spp.) fishery. Fisheries Research 216: 138-144.

DOI: 10.1016/j.fishres.2019.04.009.

Eldridge PJ, Burrell VG, Steele G. 1979. Development of a Self-Culling Blue Crab Pot. Marine 
Fisheries Review 8.

427 Fisheries Administration Bureau, MARA, PRC, 2020. 2020 China fishery statistics yearbooks.

China Agriculture Press, Beijing, China (in Chinese).

429

430

431

432

433

434

435

436

437

438

439

440

441

442

443

444

445

446

Fogarty MJ, Borden DV. 1980. Effects of trap venting in gear selectivity in the inshore Rhode

Island American lobster, Homarus americanus, fishery. Fishery Bulletin 77: 925-933.

Gandy RL, Crowley CE, Leone EH, Crawford CR. 2018. Increasing the Selectivity of the Stone Crab Menippe mercenaria Trap by the Addition of a Cull Ring. North American Journal of Fisheries Management 38. DOI: 10.1002/nafm.10232.

Guillory V, Merrell J. 1993. An evaluation of escape rings in blue crab traps. Louisiana Department of Wildlife and Fisheries, Technical Bulletin Number 44, Baton Rouge.

Guillory V, Prejean P. 1997. Blue Crab, Callinectes sapidus, Trap Selectivity Studies: Mesh Size. Marine Fisheries Review 59: 29-31.

Guillory V, Hein S. 1998. An evaluation of square and hexagonal mesh blue crab traps with and without escape rings. Journal of Shellfish Research 17: 561-562.

Guillory V, Allemand R, King K, Bare L. 2004. An Evaluation of 5.87-cm and 6.03-cm Escape Rings for Blue Crab Callinectes sapidus Traps. North American Journal of Fisheries Management 24: 1431-1434. DOI: 10.1577/M03-091.1.

Havens KJ, Bilkovic DM, Stanhope D, Angstadt K. 2009. Location, Location, Location: The Importance of Cull Ring Placement in Blue Crab Traps. Transactions of the American Fisheries Society 138: 720-724. DOI: 10.1577/T08-168.1.

Herrmann B, Sistiaga M, Nielsen KN, Larsen RB. 2012. Understanding the Size Selectivity of 
Jirapunpipat K, Phomikong P, Yokota M, Watanabe S. 2008. The effect of escape vents in 73-78. DOI: 10.1016/j.fishres.2008.06.018.

452

Kalogirou S, Pihl L, Maravelias CD, Herrmann B, Smith CJ, Papadopoulou N, Notti E, Sala A. 2019. Shrimp trap selectivity in a Mediterranean small-scale-fishery. Fisheries Research 211: 131-140. DOI: 10.1016/j.fishres.2018.11.006.

Kim D, Ko K. 1987. Fishing mechanism of pots and their modification. 2. Behavior of crab, Charybdis japonica, to net pots. Bulletin of The Korean Fishery Society 20: 348-354.

Millar RB. 1993. Incorporation of between-haul variation using bootstrapping and nonparametric estimation of selection curves. Fishery Bulletin 91: 564-572.

Montgomery SS. 2005. Effects of trap-shape, bait, and soak-time on sampling the eastern rock lobster, Jasus verreauxi. New Zealand Journal of Marine and Freshwater Research 39: 353-363. DOI: 10.1080/00288330.2005.9517316.

Nguyen KQ, Bayse SM, Donovan M, Winger PD, Løkkeborg S, Humborstad O-B. 2020. Increased catches of snow crab (Chionoecetes opilio) with luminescent-netting pots at long soak times. Fisheries Research 230: 105685.

DOI: 10.1016/j.fishres.2020.105685.

Nishiuchi S. 2001. Size Selectivity of Hair Crab Pots. Reviews in Fisheries Science 9: 13-26. DOI: $10.1080 / 20016491101672$. 
468 Olsen L, Herrmann B, Sistiaga M, Grimaldo E. 2019. Effect of gear soak time on size selection 469 in the snow crab pot fishery. Fisheries Research 214: 157-165. DOI: 10.1016/j.fishres.2019.02.005.

R Core Team (2018). R: A language and environment for statistical computing. R Foundation for Statistical Computing, Vienna, Austria.

Rotherham D, Johnson DD, Macbeth WG, Gray CA. 2013. Escape Gaps as a Management Strategy for Reducing Bycatch in Net-Covered Traps for the Giant Mud Crab Scylla serrata. North American Journal of Fisheries Management 33: 307-317. DOI: 10.1080/02755947.2012.760502.

Song H, Yu C, Xue L, Yao G. 2006. Commercial shellfishs in the East China sea. China Ocean Press, Beijing, China (in Chinese).

Stasko AB. 1975. Modified Lobster Traps for Catching Crabs and Keeping Lobsters Out. Journal of the Fisheries Research Board of Canada 32: 2515-2520. DOI: $10.1139 / \mathrm{f} 75-290$.

Tallack SML. 2007. Escape ring selectivity, bycatch, and discard survivability in the New England fishery for deep-water red crab, Chaceon quinquedens. ICES Journal of Marine Science 64: 1579-1586. DOI: 10.1093/icesjms/fsm107.

Tang Y, Liu Y, Liu C, Zhang W. 2019. Improving the accordion-shaped trap selectivity for black rockfish by mounting escape vents: A case study from the small-scale fishery in Shandong, China. Fisheries Research 219: 105317.

DOI: 10.1016/j.fishres.2019.105317. 
489 Treble RJ, Millar RB, Walker TI. 1998. Size-selectivity of lobster pots with escape-gaps:

490 application of the SELECT method to the southern rock lobster (Jasus edwardsii) fishery in $491 \quad$ Victoria, Australia. Fisheries Research 34: 289-305.

492 Uhlmann SS, Broadhurst MK. 2015. Mitigating unaccounted fishing mortality from gillnets and traps. Fish and Fisheries 16: 183-229. DOI: 10.1111/faf.12049.

494 495

496

497

498

499

500

501

502

503

504

505

506

507

508

509

Vazquez Archdale M, Anraku K, Yamamoto T, Higashitani N. 2003. Behavior of the Japanese rock crab 'Ishigani' Charybdis japonica towards two collapsible baited pots: Evaluation of capture effectiveness. Fisheries Science 69: 785-791.

DOI: 10.1046/j.1444-2906.2003.00687.x.

Vazquez Archdale M, Kuwahara O. 2005. Comparative fishing trials for Charybdis japonica using collapsible box-shaped and dome-shaped pots. Fisheries Science 71: 1229-1235. DOI: 10.1111/j.1444-2906.2005.01087.x.

Vazquez Archdale M, Añasco CP, Hiromori S. 2006. Comparative fishing trials for invasive swimming crabs Charybdis japonica and Portunus pelagicus using collapsible pots. Fisheries Research 82: 50-55.

DOI: $10.1016 /$ j.fishres.2006.08.009.

Vazquez Archdale M, Kariyazono L, Añasco CP. 2006. The effect of two pot types on entrance rate and entrance behavior of the invasive Japanese swimming crab Charybdis japonica. Fisheries Research 77: 271-274.

DOI: 10.1016/j.fishres.2005.11.012.

Vazquez Archdale M, Anasco CP, Kawamura Y, Tomiki S. 2007. Effect of two collapsible pot 

85: 202-209.

Wileman D, Ferro RST, Fonteyne R, Millar RB. 1996. Manual of methods of measuring the selectivity of towed fishing gears. ICES Cooperative Research Report 215: 1-126.

Winger PD, Walsh PJ. 2007. The feasibility of escape mechanisms in conical snow crab traps. ICES Journal of Marine Science 64: 1587-1591. DOI: $10.1093 /$ icesjms/fsm125.

Winger PD, Walsh PJ. 2011. Selectivity, efficiency, and underwater observations of modified trap designs for the snow crab (Chionoecetes opilio) fishery in Newfoundland and Labrador. Fisheries Research 109: 107-113. 533. DOI: 10.1046/j.1444-2906.2002.00458.x.

Yang B, Tang Y, Liang Z. 2011. Selectivity of escape-hole size in tube traps for white-spotted conger Conger myriaster. Chinese Journal of Oceanology and Limnology 29: 1041-1047. DOI: $10.1007 / \mathrm{s} 00343-011-0086-7$.

Yu C, Song H, Yao G, Shen X. 2003. Study on rational utilization of crab resources in the inshore water of Zhejiang [In Chinese with English abstract]. Marine Fisheries 25: 136141. 
531 pots for swimming crab Portunus trituberculatus in the East China Sea. Aquaculture and $532 \quad$ Fisheries S2468550X20300502.

$533 \quad$ DOI: $10.1016 /$ j.aaf.2020.04.008.

534 Zhang P, Zhang X. 2013. Ingress behavior and escape vent selectivity of

535 Charybdis japonica in the cage net [In Chinese with English abstract]. Journal of Fishery $536 \quad$ Sciences of China 20: 338-345.

537 Zhang P, Li C, Li W, Zhang X. 2016. Effect of an escape vent in accordion-shaped traps on the $538 \quad$ catch and size of Asian paddle crabs Charybdis japonica in an artificial reef area. Chinese $539 \quad$ Journal of Oceanology and Limnology 34: 1238-1246.

$540 \quad$ DOI: $10.1007 / \mathrm{s} 00343-016-5114-1$. 


\section{Figure 1}

Experimental gear configuration and operation.

(A) Illustration of the modified round pot and escape vent size $(70 \times 20,70 \times 25,70 \times 30$, and $70 \times 35 \mathrm{~mm}$ ). (B) Deployment of pots in a single string. Each string had ten pots, and a total of 5 strings were used during the sea trials. The pots were deployed $50 \mathrm{~m}$ apart with two anchors each weighing $15 \mathrm{~kg}$ at the ends. 


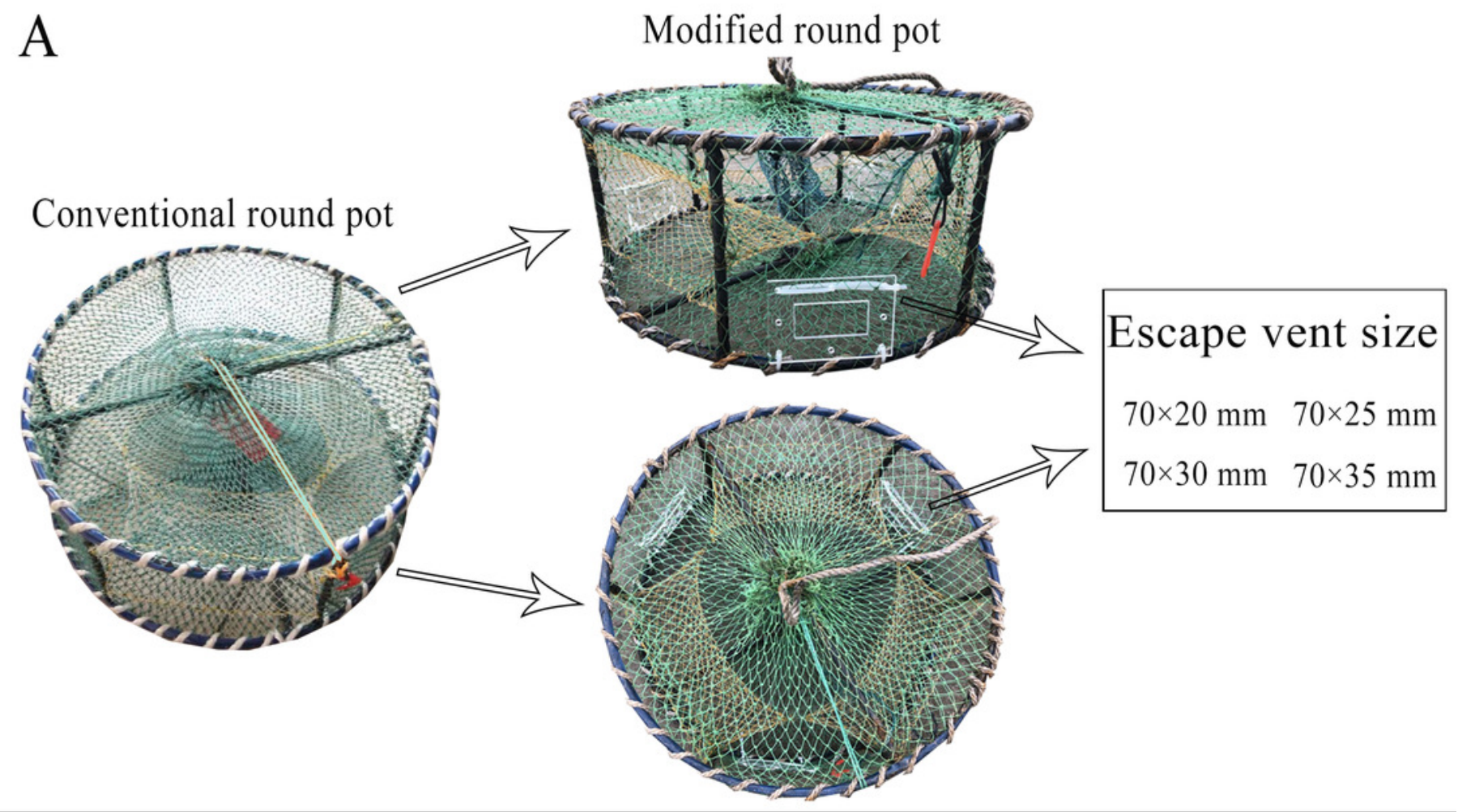

\section{B}

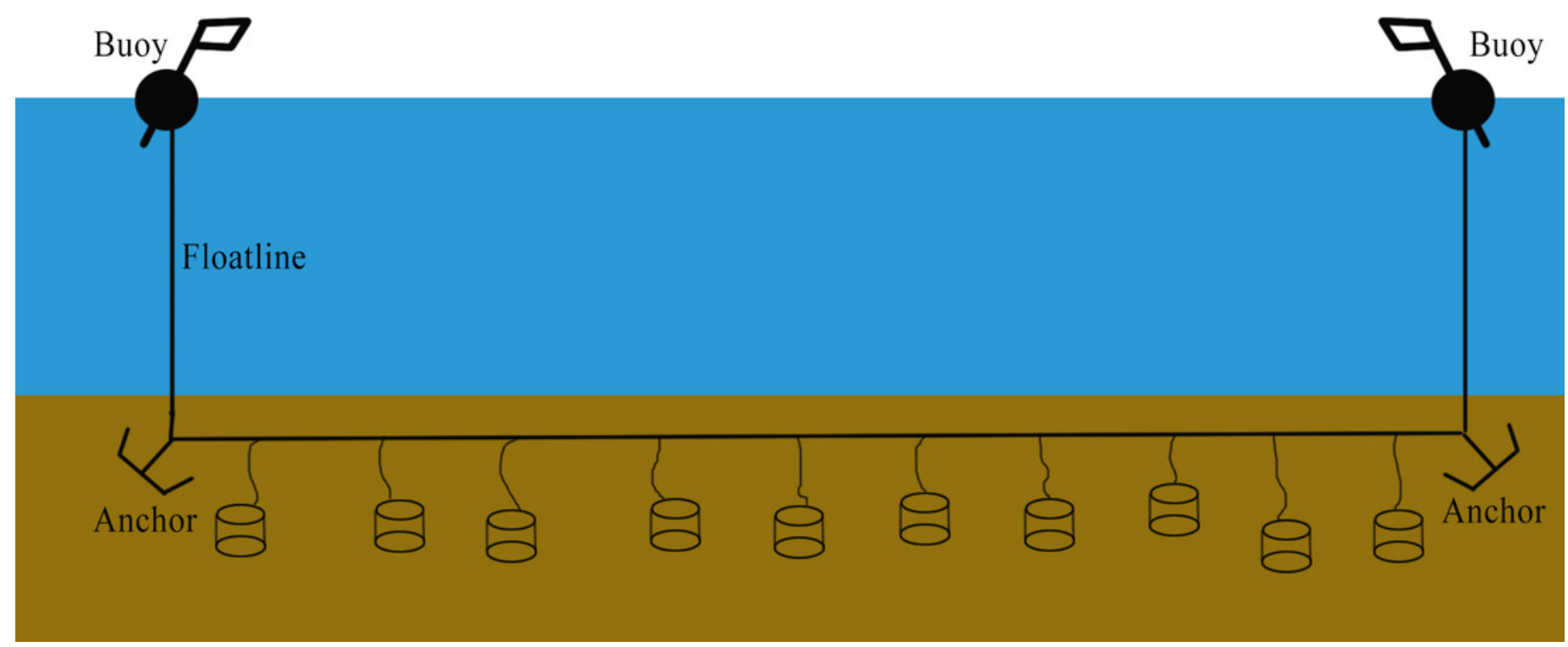


Figure 2

The location of the sampling sites in the Yellow Sea of China.

The substrate type is a mixture of mud, sand, and rock.

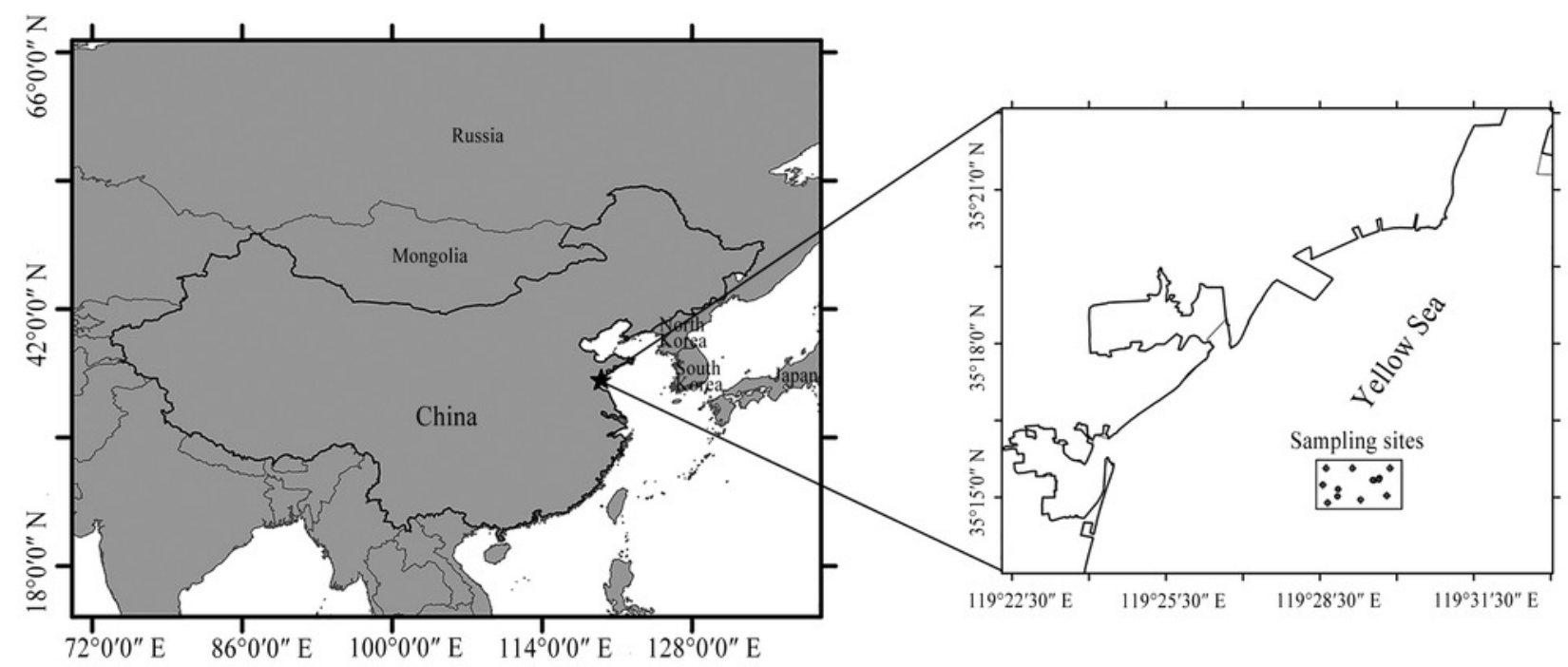


Figure 3

Mean size selectivity curves estimated for $C$. japonica in pots with different escape vent sizes (control, $70 \times 20,70 \times 25,70 \times 30$, and $70 \times 35 \mathrm{~mm}$ ).

Thick solid lines represent the mean size selectivity curves. The dashed curves represent 95\% confidence intervals. The vertical dashed line indicates the MLS of carapace height (27 $\mathrm{mm}$ ). The gray lines represent the carapace height distribution of $C$. japonica caught by each type of pot. 


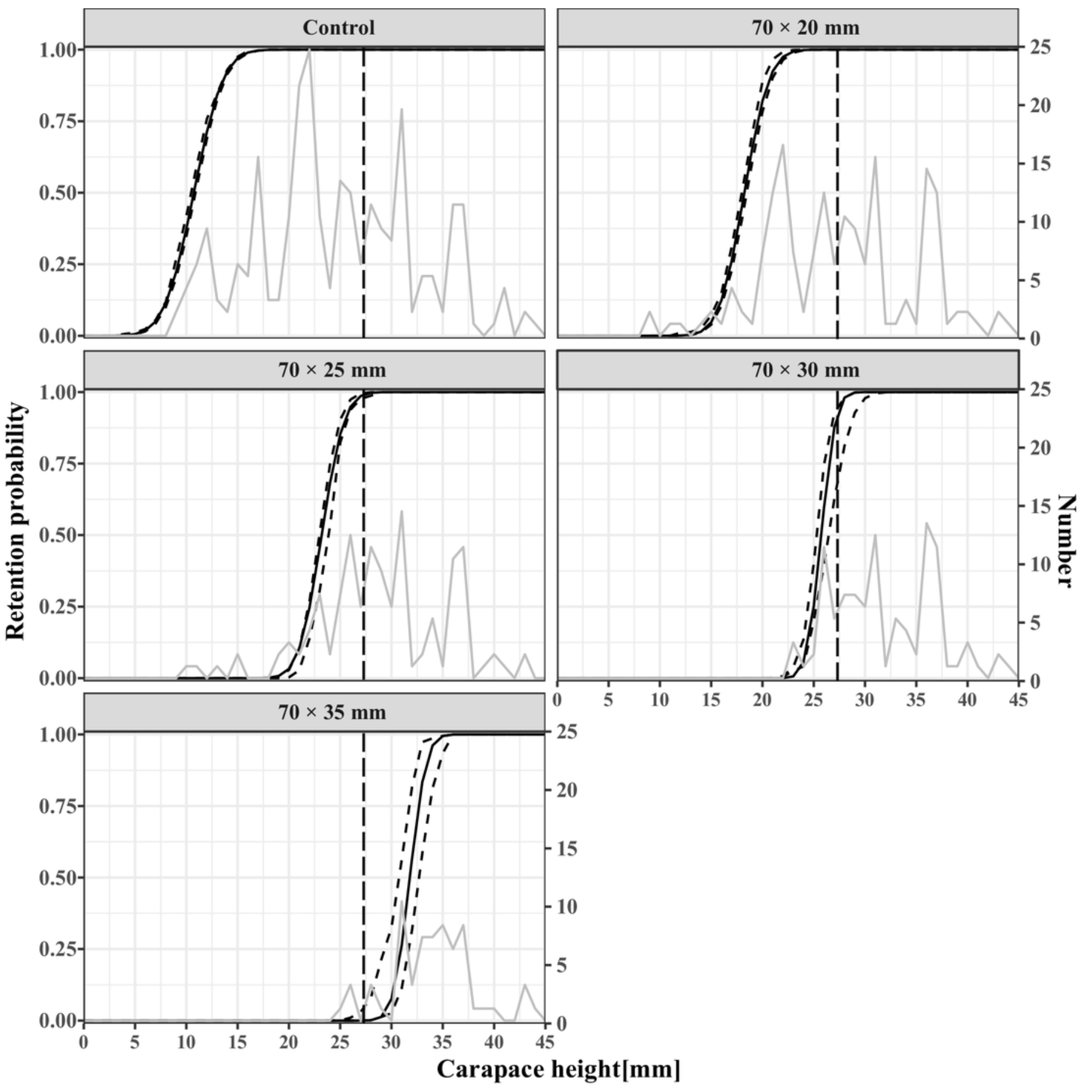


Figure 4

Estimated relative size selectivity curves.

Thick solid curves denote the proportion of individuals caught in the five types of pots to the total catch. The dashed curves indicate the $95 \%$ confidence intervals for the fitted size selectivity curves. The hollow dots represent the experimental data. The horizontal gray baseline at 0.20 indicates equal catch efficiency, and the vertical line represents the MLS of carapace height $(27 \mathrm{~mm})$. 


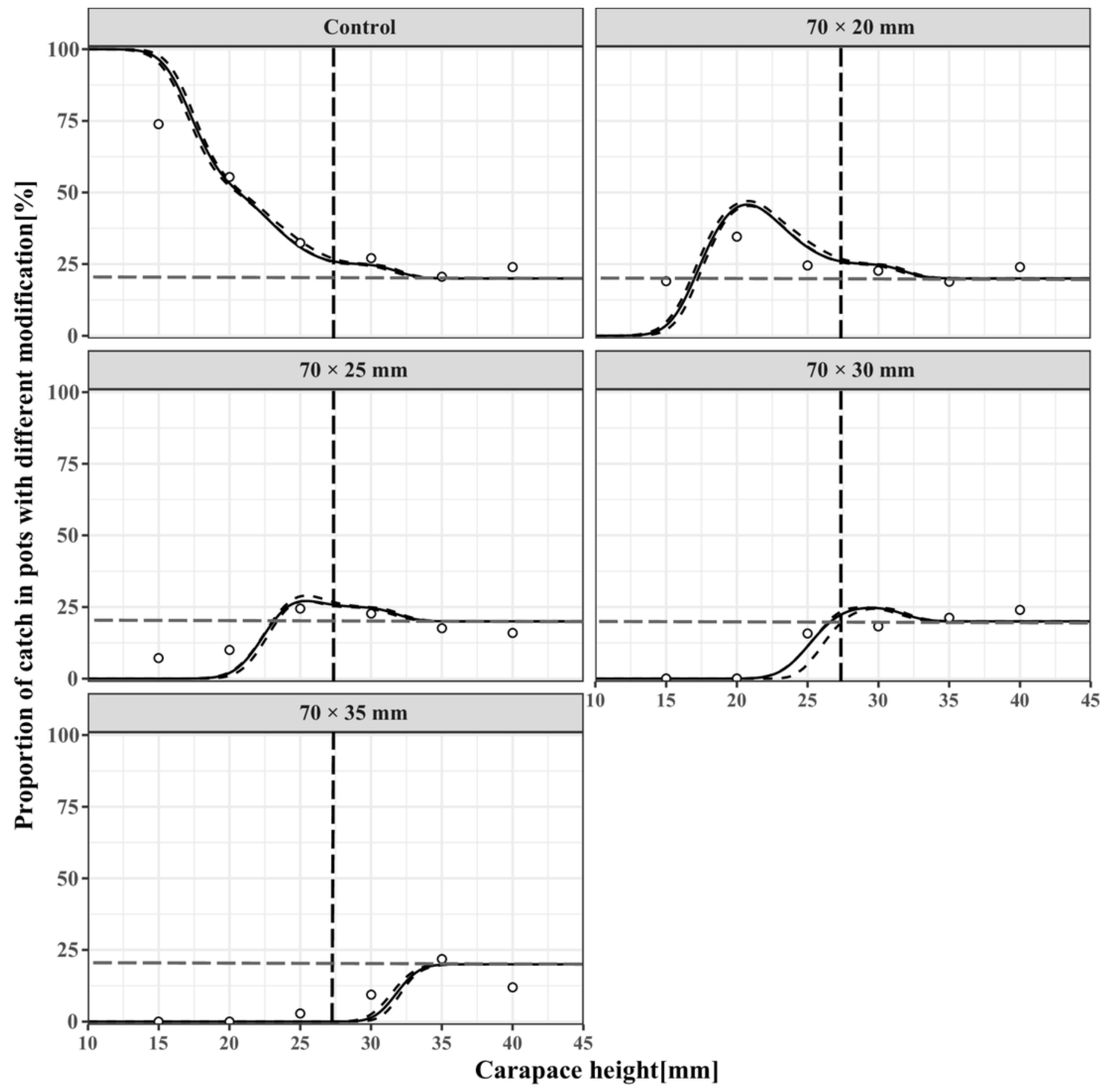


Figure 5

Difference in the retention rates for pots between the escape vent sizes of control and $70 \times 20 \mathrm{~mm}$ (Delta 1), $70 \times 20$ and $70 \times 25 \mathrm{~mm}$ (Delta 2), $70 \times 25$ and $70 \times 30 \mathrm{~mm}$ (Delta 3), and $70 \times 30$ and $70 \times 35 \mathrm{~mm}$ (Delta 4).

Thick solid curves and dotted curves indicate the mean and $95 \%$ confidence intervals for the differences in fitted size selectivity curves, respectively. The vertical dashed line represents the MLS of carapace height $(27 \mathrm{~mm})$. 

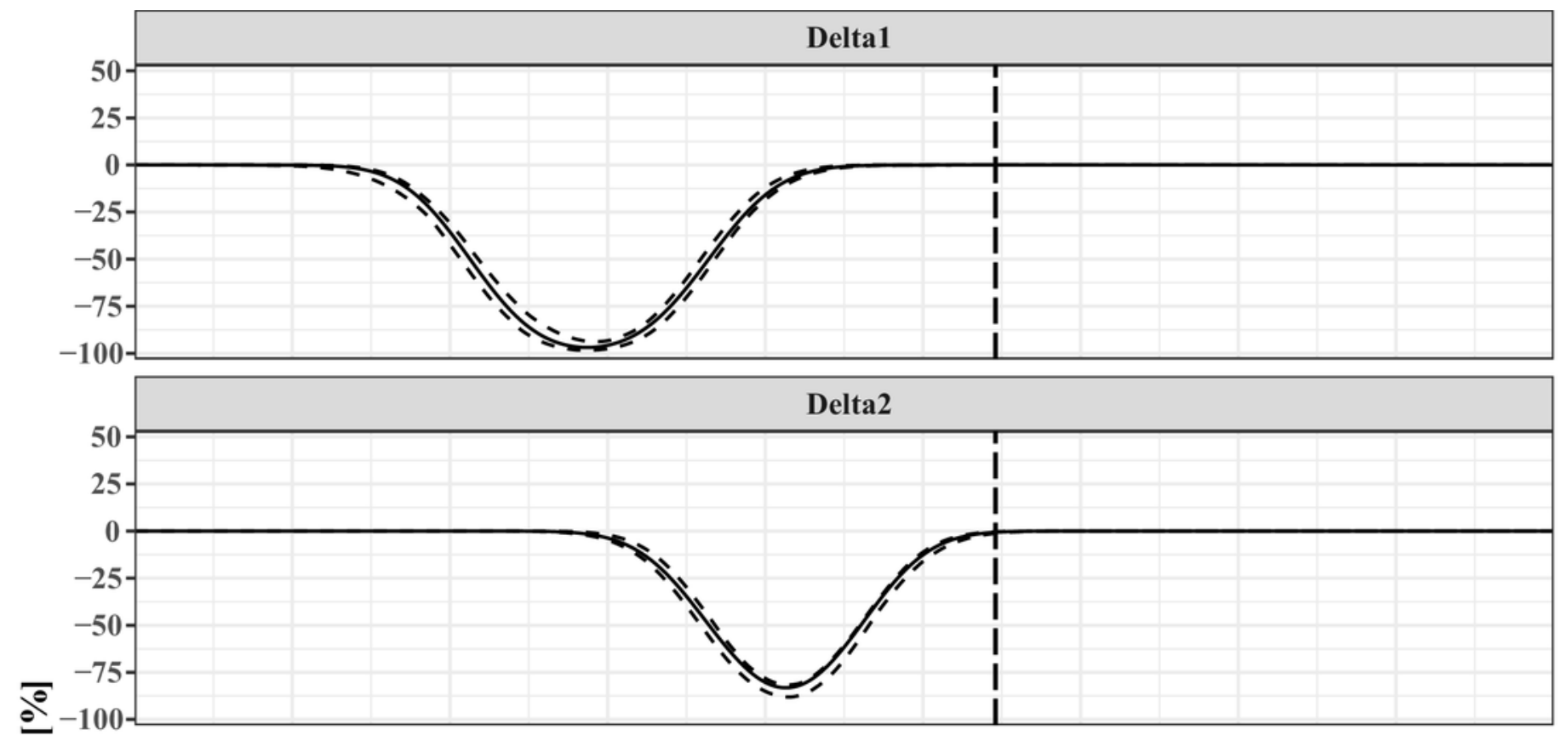

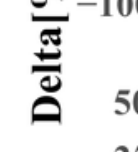
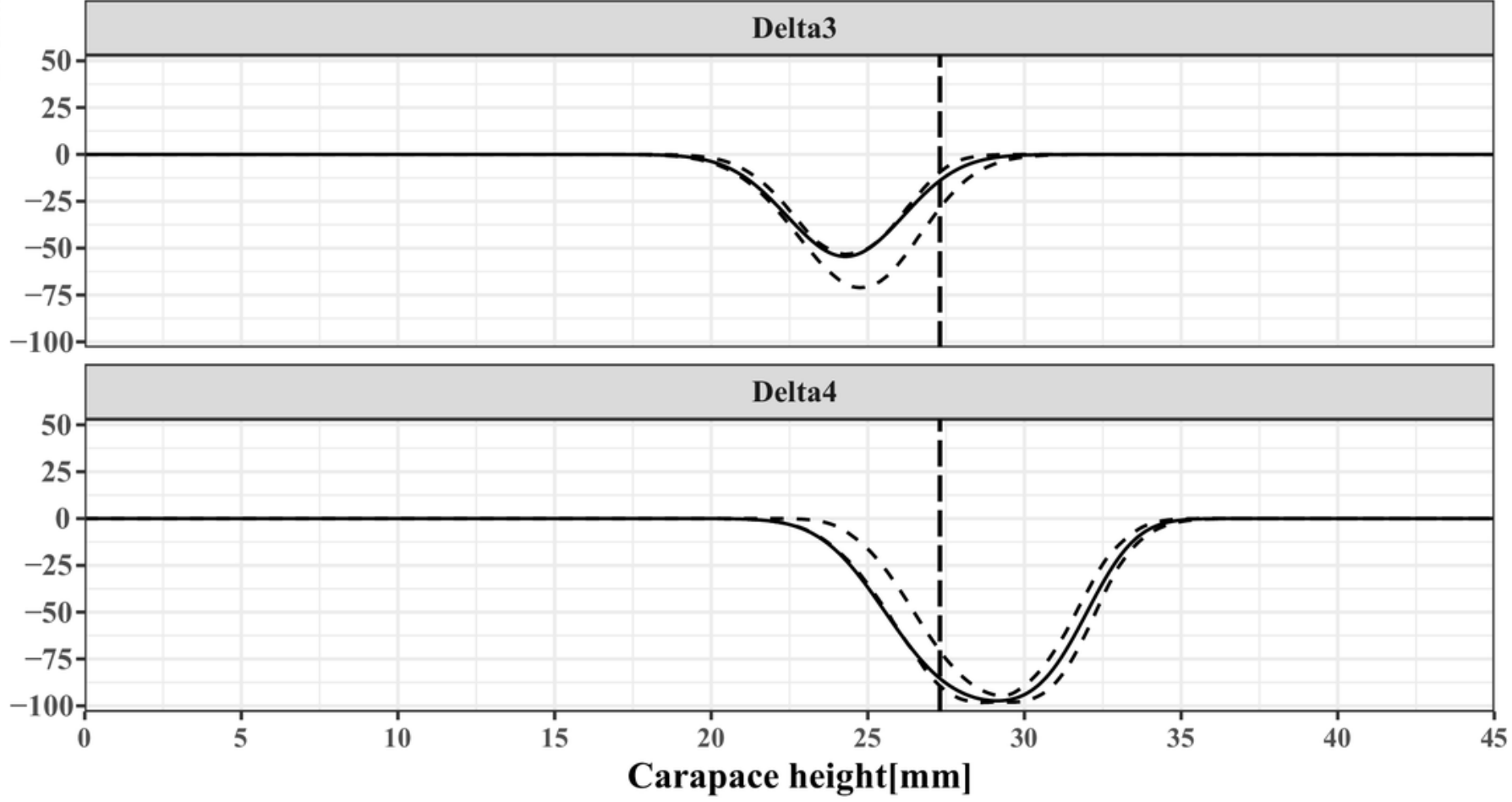
Table $\mathbf{1}$ (on next page)

Details of catch data from the sea trials. 


\begin{tabular}{|c|c|c|c|c|c|c|c|c|c|c|}
\hline \multirow[b]{2}{*}{ Trip } & \multirow[b]{2}{*}{ Pot type } & \multirow[b]{2}{*}{ Date } & \multirow[b]{2}{*}{ Soak time (h) } & \multicolumn{3}{|c|}{ C. japonica } & \multicolumn{4}{|c|}{ Bycatch } \\
\hline & & & & $\begin{array}{l}\text { Total no. } \\
\text { caught }\end{array}$ & $\begin{array}{l}\mathrm{CH} \text { range } \\
(\mathrm{mm})\end{array}$ & $\begin{array}{l}\text { Average } C H \\
( \pm \mathrm{SD})\end{array}$ & $\begin{array}{l}\text { Rapana } \\
\text { venosa }\end{array}$ & $\begin{array}{l}\text { Palaemon } \\
\text { ortmanni }\end{array}$ & $\begin{array}{l}\text { Pennahia } \\
\text { argentata }\end{array}$ & Asterinidae \\
\hline \multirow{5}{*}{1} & Control & $20 / 08 / 2020$ & 48 & 33 & $12-37$ & $22.7( \pm 7.9)$ & 10 & 2 & 1 & 3 \\
\hline & $70 \times 20 \mathrm{~mm}$ & $20 / 08 / 2020$ & 48 & 18 & $17-39$ & $28.0( \pm 6.1)$ & 6 & 2 & 1 & 2 \\
\hline & $70 \times 25 \mathrm{~mm}$ & $20 / 08 / 2020$ & 48 & 14 & $20-39$ & $29.6( \pm 5.4)$ & 4 & 1 & 0 & 3 \\
\hline & $70 \times 30 \mathrm{~mm}$ & $20 / 08 / 2020$ & 48 & 10 & $26-40$ & $32.0( \pm 4.3)$ & 4 & 1 & 2 & 2 \\
\hline & $70 \times 35 \mathrm{~mm}$ & $20 / 08 / 2020$ & 48 & 7 & $29-37$ & $33.0( \pm 2.6)$ & 3 & 0 & 1 & 1 \\
\hline \multirow{5}{*}{2} & Control & $22 / 08 / 2020$ & 48 & 21 & $21-43$ & $27.9( \pm 6.2)$ & 8 & 1 & 2 & 4 \\
\hline & $70 \times 20 \mathrm{~mm}$ & $22 / 08 / 2020$ & 48 & 17 & $15-36$ & $27.2( \pm 6.0)$ & 5 & 0 & 1 & 4 \\
\hline & $70 \times 25 \mathrm{~mm}$ & $22 / 08 / 2020$ & 48 & 14 & $19-37$ & $29.6( \pm 4.9)$ & 2 & 1 & 3 & 1 \\
\hline & $70 \times 30 \mathrm{~mm}$ & $22 / 08 / 2020$ & 48 & 10 & $26-40$ & $31.2( \pm 4.5)$ & 3 & 0 & 1 & 2 \\
\hline & $70 \times 35 \mathrm{~mm}$ & $22 / 08 / 2020$ & 48 & 7 & $31-35$ & $32.7( \pm 1.6)$ & 2 & 0 & 0 & 3 \\
\hline \multirow{5}{*}{3} & Control & $24 / 08 / 2020$ & 48 & 27 & $12-41$ & $25.1( \pm 7.3)$ & 7 & 3 & 1 & 5 \\
\hline & $70 \times 20 \mathrm{~mm}$ & $24 / 08 / 2020$ & 48 & 17 & $15-37$ & $27.2( \pm 6.0)$ & 5 & 1 & 2 & 3 \\
\hline & $70 \times 25 \mathrm{~mm}$ & $24 / 08 / 2020$ & 48 & 14 & $21-43$ & $31.0( \pm 6.7)$ & 6 & 0 & 0 & 3 \\
\hline & $70 \times 30 \mathrm{~mm}$ & $24 / 08 / 2020$ & 48 & 9 & $25-37$ & $31.8( \pm 4.4)$ & 3 & 1 & 0 & 2 \\
\hline & $70 \times 35 \mathrm{~mm}$ & $24 / 08 / 2020$ & 48 & 6 & $31-36$ & $33.7( \pm 1.7)$ & 3 & 0 & 0 & 2 \\
\hline \multirow{5}{*}{4} & Control & $26 / 08 / 2020$ & 47 & 42 & $9-41$ & $21.9( \pm 7.5)$ & 8 & 2 & 3 & 4 \\
\hline & $70 \times 20 \mathrm{~mm}$ & $26 / 08 / 2020$ & 47 & 19 & $9-43$ & $26.3( \pm 8.1)$ & 5 & 2 & 0 & 2 \\
\hline & $70 \times 25 \mathrm{~mm}$ & $26 / 08 / 2020$ & 47 & 14 & $15-37$ & $28.2( \pm 5.8)$ & 3 & 1 & 1 & 2 \\
\hline & $70 \times 30 \mathrm{~mm}$ & $26 / 08 / 2020$ & 47 & 11 & $23-37$ & $30.5( \pm 4.5)$ & 2 & 0 & 1 & 4 \\
\hline & $70 \times 35 \mathrm{~mm}$ & $26 / 08 / 2020$ & 47 & 6 & $25-37$ & $31.2( \pm 4.4)$ & 2 & 0 & 1 & 2 \\
\hline \multirow{5}{*}{5} & Control & $28 / 08 / 2020$ & 48 & 14 & $23-43$ & $30.5( \pm 5.0)$ & 5 & 0 & 2 & 2 \\
\hline & $70 \times 20 \mathrm{~mm}$ & $28 / 08 / 2020$ & 48 & 19 & $11-40$ & $27.5( \pm 7.7)$ & 7 & 1 & 1 & 4 \\
\hline & $70 \times 25 \mathrm{~mm}$ & $28 / 08 / 2020$ & 48 & 14 & $15-37$ & $27.8( \pm 6.0)$ & 5 & 3 & 0 & 2 \\
\hline & $70 \times 30 \mathrm{~mm}$ & $28 / 08 / 2020$ & 48 & 11 & $24-37$ & $31.2( \pm 4.3)$ & 4 & 1 & 1 & 0 \\
\hline & $70 \times 35 \mathrm{~mm}$ & $28 / 08 / 2020$ & 48 & 6 & $26-37$ & $32.3( \pm 4.1)$ & 3 & 0 & 0 & 4 \\
\hline
\end{tabular}




\begin{tabular}{|c|c|c|c|c|c|c|c|c|c|c|}
\hline \multirow{5}{*}{6} & Control & $30 / 08 / 2020$ & 48 & 29 & $11-41$ & $25.1( \pm 8.2)$ & 9 & 1 & 1 & 6 \\
\hline & $70 \times 20 \mathrm{~mm}$ & $30 / 08 / 2020$ & 48 & 20 & $12-43$ & $28.1( \pm 7.6)$ & 4 & 0 & 2 & 3 \\
\hline & $70 \times 25 \mathrm{~mm}$ & $30 / 08 / 2020$ & 48 & 14 & $13-37$ & $27.9( \pm 6.2)$ & 5 & 0 & 2 & 3 \\
\hline & $70 \times 30 \mathrm{~mm}$ & $30 / 08 / 2020$ & 48 & 14 & $26-44$ & $33.1( \pm 5.4)$ & 1 & 0 & 0 & 3 \\
\hline & $70 \times 35 \mathrm{~mm}$ & $30 / 08 / 2020$ & 48 & 8 & $26-45$ & $35.0( \pm 5.6)$ & 2 & 0 & 0 & 1 \\
\hline \multirow{5}{*}{7} & Control & $01 / 09 / 2020$ & 49 & 36 & $10-44$ & $23.2( \pm 8.3)$ & 5 & 2 & 0 & 3 \\
\hline & $70 \times 20 \mathrm{~mm}$ & $01 / 09 / 2020$ & 49 & 19 & 9-39 & $27.2( \pm 7.4)$ & 6 & 2 & 1 & 4 \\
\hline & $70 \times 25 \mathrm{~mm}$ & $01 / 09 / 2020$ & 49 & 14 & $11-40$ & $28.4( \pm 7.1)$ & 3 & 0 & 1 & 3 \\
\hline & $70 \times 30 \mathrm{~mm}$ & $01 / 09 / 2020$ & 49 & 13 & $23-43$ & $33.1( \pm 5.8)$ & 5 & 0 & 1 & 1 \\
\hline & $70 \times 35 \mathrm{~mm}$ & $01 / 09 / 2020$ & 49 & 11 & $31-43$ & $37.3( \pm 3.5)$ & 0 & 1 & 1 & 1 \\
\hline \multirow{5}{*}{8} & Control & $03 / 09 / 2020$ & 47 & 21 & $18-41$ & $28.0( \pm 6.1)$ & 6 & 2 & 2 & 5 \\
\hline & $70 \times 20 \mathrm{~mm}$ & $03 / 09 / 2020$ & 47 & 18 & $17-41$ & $27.5( \pm 7.4)$ & 4 & 1 & 2 & 4 \\
\hline & $70 \times 25 \mathrm{~mm}$ & $03 / 09 / 2020$ & 47 & 14 & $10-40$ & $28.2( \pm 7.1)$ & 4 & 1 & 0 & 2 \\
\hline & $70 \times 30 \mathrm{~mm}$ & $03 / 09 / 2020$ & 47 & 11 & $25-43$ & $32.4( \pm 5.0)$ & 3 & 1 & 0 & 2 \\
\hline & $70 \times 35 \mathrm{~mm}$ & $03 / 09 / 2020$ & 47 & 7 & $28-43$ & $34.4( \pm 4.5)$ & 4 & 1 & 0 & 1 \\
\hline \multirow{5}{*}{9} & Control & $05 / 09 / 2020$ & 48 & 27 & $10-37$ & $24.6( \pm 7.8)$ & 2 & 3 & 1 & 4 \\
\hline & $70 \times 20 \mathrm{~mm}$ & $05 / 09 / 2020$ & 48 & 18 & $17-43$ & $28.1( \pm 6.6)$ & 6 & 2 & 1 & 3 \\
\hline & $70 \times 25 \mathrm{~mm}$ & $05 / 09 / 2020$ & 48 & 14 & $20-43$ & $29.9( \pm 6.3)$ & 4 & 1 & 2 & 2 \\
\hline & $70 \times 30 \mathrm{~mm}$ & $05 / 09 / 2020$ & 48 & 10 & $23-37$ & $31.6( \pm 4.7)$ & 3 & 0 & 1 & 1 \\
\hline & $70 \times 35 \mathrm{~mm}$ & $05 / 09 / 2020$ & 48 & 6 & $31-36$ & $33.3( \pm 1.6)$ & 2 & 0 & 0 & 1 \\
\hline \multirow{5}{*}{ Total } & Control & & $47-49$ & 250 & $9-44$ & $24.7( \pm 7.8)$ & 60 & 16 & 13 & 36 \\
\hline & $70 \times 20 \mathrm{~mm}$ & & $47-49$ & 165 & $9-43$ & $27.4( \pm 7.1)$ & 48 & 11 & 11 & 29 \\
\hline & $70 \times 25 \mathrm{~mm}$ & & $47-49$ & 126 & $10-43$ & $29.0( \pm 6.3)$ & 36 & 9 & 9 & 21 \\
\hline & $70 \times 30 \mathrm{~mm}$ & & $47-49$ & 99 & $23-44$ & $31.9( \pm 4.9)$ & 28 & 4 & 7 & 17 \\
\hline & $70 \times 35 \mathrm{~mm}$ & & $47-49$ & 64 & $25-45$ & $34.0( \pm 4.1)$ & 21 & 2 & 3 & 16 \\
\hline
\end{tabular}




\section{Table 2 (on next page)}

Estimated parameters and 95\% confidence intervals (Cls) using the Logistic model.

$\mathrm{CH} 50$ is the carapace height with a $50 \%$ retention rate; $\mathrm{SR}$ is the selection range; $\mathrm{P}$ is the relative fishing intensity. DOF is the degree of freedom; $p$-value is the percent of deviance explained. $\mathrm{CH} 50$ and SR are in $\mathrm{mm}$; Cls are in italics. 
1

\begin{tabular}{llllll}
\hline & Control & $70 \times 20 \mathrm{~mm}$ & $70 \times 25 \mathrm{~mm}$ & $70 \times 30 \mathrm{~mm}$ & $70 \times 35 \mathrm{~mm}$ \\
\hline CH50 & 10.73 & 18.23 & 23.19 & 25.73 & 31.79 \\
& $10.45-10.91$ & $17.98-18.43$ & $22.93-23.85$ & $25.02-26.25$ & $30.80-32.52$ \\
SR & 4.97 & 4.23 & 3.79 & 2.40 & 2.74 \\
P & $4.61-5.28$ & $3.93-4.54$ & $3.60-4.13$ & $2.11-2.52$ & $2.38-3.05$ \\
Deviance & 0.80 & 0.19 & 0.18 & 0.22 & 0.21 \\
DOF & 8 & 0.71 & 0.97 & 1.26 & 2.03 \\
$p$-value & 0.99 & 8 & 8 & 5 & 5 \\
\hline 2 & & 0.99 & 0.99 & 0.94 & 0.84
\end{tabular}




\section{Table 3 (on next page)}

Carapace height-based percentage and Efron 95\% confidence intervals (in italics) of fractions below ( $n P-)$ and above $(n P+)$ the MLS of carapace height $(27 \mathrm{~mm})$ in number of individuals and the ratio ( $n R$ atio) between $n P$ - and $n P+$. 
1

\begin{tabular}{lllll}
\hline & $70 \times 20 \mathrm{~mm}$ & $70 \times 25 \mathrm{~mm}$ & $70 \times 30 \mathrm{~mm}$ & $70 \times 35 \mathrm{~mm}$ \\
\hline$n P-$ & 48.32 & 24.83 & 5.37 & 2.68 \\
& $45.33-51.68$ & $21.34-28.28$ & $3.95-6.16$ & $0.00-5.52$ \\
$n P+$ & 92.08 & 88.12 & 90.10 & 59.41 \\
& $85.44-98.99$ & $80.37-96.87$ & $83.81-99.02$ & $49.51-69.00$ \\
$n$ Ratio & 0.52 & 0.28 & 0.06 & 0.05 \\
& $0.46-0.61$ & $0.22-0.35$ & $0.04-0.07$ & $0.00-0.12$ \\
$w P-$ & 54.31 & 26.95 & 6.79 & 5.36 \\
& $49.74-59.31$ & $22.16-31.44$ & $4.40-9.40$ & $0.00-10.63$ \\
\multirow{2}{*}{$w P+$} & 93.33 & 85.68 & 95.60 & 68.57 \\
& $79.14-106.59$ & $74.41-100.00$ & $85.29-107.22$ & $55.55-83.24$ \\
& 0.58 & 0.31 & 0.07 & 0.08 \\
\hline \multirow{2}{*}{ wRatio } & $0.47-0.73$ & $0.24-0.41$ & $0.04-0.10$ & $0.00-0.17$ \\
\hline
\end{tabular}

2 